Journal of Applied Pharmaceutical Science Vol. 7 (04), pp. 096-102, April, 2017

Available online at http://www.japsonline.com

DOI: $10.7324 / \mathrm{JAPS} .2017 .70413$

ISSN 2231-3354 (cc) BY-NC-SA

\title{
Fibrinolysis parameters in the acute and post ischemic stroke patients
}

\author{
Tetiana Katrii*, Viktoria Shandyuk, Natalia Raksha, Tetiana Halenova, Olexiy Shershnov, Volodymyr Melnyk, \\ Olexiy Savchuk \\ Educational and Scientific Center 'Institute of Biology', Taras Shevchenko National University of Kyiv, Ukraine. Bogomolets National Medical \\ University, Kyiv, Ukraine.
}

\begin{tabular}{l}
\hline ARTICLE INFO \\
\hline Article history: \\
Received on: $12 / 12 / 2016$ \\
Accepted on: $23 / 01 / 2017$ \\
Available online: $30 / 04 / 2017$ \\
\hline Key words: \\
Ischemic stroke, PAI-1, t-PA, \\
Plasminogen, $\alpha 2$-antiplasmin, \\
FXII-dependent fibrinolysis, \\
Euglobulin lysis time. \\
\hline
\end{tabular}

\section{INTRODUCTION}

A critical prevalence of stroke bring high mortality and significant disability population, a fairly high percentage of stroke recurrent are evidence of the relevance of the stroke problem in medical and social terms (Adamson et al., 2004; Jonathan et al., 2002). The pathogenesis of ischemic stroke consists of a number of mechanisms, including disturbances in platelets, coagulation, anticoagulation and fibrinolytic links of haemostasis play a key role (Wolfe, 2000). Fibrinolytic capacity of blood plasma is able to characterize the ability to organism to confront possible thrombotic threats in condition of hypercoagulation. Even in some pathological conditions which on its beginning are unrelated with haemostasis disorders, there are certain decreases in fibrinolytic potential, indicating in this way a possible threat of thrombotic complications (Lowe et al., 2002; Mehta et al., 2003; Swarowska et al., 2014). Especially important is evaluation of fibrinolytic potential of haemostasis

\footnotetext{
* Corresponding Author

Tetiana Katrii, Educational and Scientific Center 'Institute of Biology', Taras Shevchenko National University of Kyiv, Ukraine.

Email: tetiana.katrii@gmail.com
}

after a certain time after the disease as a guarantee of absence of the risk of repetitions. As known firstly the term "fibrinolysis" was proposed in 1893 by A. Dastre, to describe the physiological process of fibrin lysis (Macfarlane et al., 1946; Vyeremyeyenko et al., 1988).

Intensive study of fibrinolysis process started in the $50 \mathrm{~s}$ of the XX century. Key proenzyme of the fibrinolysis system is plasminogen $(\mathrm{Pg})$ - the single stranded plasma glycoprotein with a molecular weight $92 \mathrm{kDa}$, which after activation of endogenous or exogenous activators is converted to the active enzyme (Wallen and Wiman, 1980). Plasminogen is found in all body fluids, some tissues and blood components (Dobrovolsky et al., 2002; Zubayrov, 2000; Lijnen, 1996). Plasminogen circulates in the blood in the monomeric form, in combination with a2-antiplasmin or fibrinogen (Collen and Lijnen, 1987). Plasminogen is synthesized predominantly by the liver cells, although its synthesis was detected in the kidneys, eosinophils, in brain microglia cells and testis (Raum, 1980). Normally, the concentration of plasminogen in the blood varies within the limits $1.2-2 \mu \mathrm{kM}$, however, plasminogen level in the blood varies with different physiological processes (Lijnen, 1996). 
Actions of fibrinolysis system are provided by a set of enzymes - activators, which are capable to convert plasminogen into its active form - plasmin. First of all, potential fibrinolytic activity is stipulated to (tissue plasminogen activator) tPA as well as inhibitors such as plasminogen activator inhibitor (PAI), or $\alpha 2-$ antiplasmin which are inhibitors of serine proteases, insignificant impact also belong to FXIIa (Smith et al., 1985). Thus the most defining role belongs to TAP i PAI-1 in the regulation of enzymatic lysis of fibrin clots (Katrii et al., 2016).

Tissue plasminogen activator (tPA) is the only proteinase hemostasis which is constantly secreted by endothelial cells in the active form (Dobrovolsky and Titaeva, 2002). tPA - single stranded glycoprotein with a molecular weight $70 \mathrm{kDa}$, a doublestranded molecule is formed due to the hydrolysis of the peptide bond by plasmin, kallikrein or factor FXa. Under physiological conditions, tPA activates Pg preferably in the presence of macromolecules (fibrin or other component of extracelulare matrix) or cellular receptors (Silverstein et al., 1985). Upon activation of plasminogen occurs reorganization of its in active double-stranded form - plasmin, due to the specific peptide bond cleavage. At the same time two strands are linked together by two disulfide bridges. In most cases the single-stranded form of serine proteases are inactive proenzymes, tPA is an exception to this rule is formed by the active center, whereby shows its catalytic activity and exhibits the ability to bind to the inhibitors, such as PAI Dobrovolsky and Titaeva, 2002; Vyeremyeyenko et al., 1988; Lijnen, 1996).

There is also the factor XIIa (Hageman factor) dependent activation pathway of plasminogen is associated with activation of kallekrein-kinin system and the complement system. However, according to this pathway activation plays a nonsignificant role in fibrinolysis (Lijnen, 2001; Ichinose et al., 1986). It is known that patients who have a deficiency of the factors (factor XII, prekallikrein, high molecular kininogen) of the contact phase of blood coagulation may suffer from thrombosis due to insufficient activation of fibrinolysis (Barkagan, 1988).

PAI-1 is a single stranded glycoprotein with a molecular weight $52 \mathrm{kDa}$, whose half-life in the bloodstream is 5 to 15 minutes. Up to $40 \%$ tPA is in the complex form with PAI-1 (in ratio 1:1). Under physiological conditions, in the plasma PAI is a 3 molecular forms (Stefansson et al., 1998; Debrock and Declerck, 1997; Alessi et al., 1991). PAI-1 is synthesized by endothelial cells and megakaryocytes. Upon activation of platelets during thrombus formation PAI- 1 secreted from the $\alpha$-granules, which leads to a high local concentration of the inhibitor and stabilize the fibrin clot matrix (Dobrovolsky and Titaeva, 2002). The literature suggests the hypothesis that high levels of PAI-1 in the blood line can cause damage to the vessel walls. But the role of a general or local increasing of the PAI-1 level in the development of atherotrombotic phenomena still is contradictory. However, there is an assumption that the low level or absence of PAI-1 leads to bleeding or blood clotting delay (Henri et al., 1997).

$\alpha 2$-antiplasmin is synthesized in the liver and secreted as a single stranded glycoprotein with a molecular weight of 67
kDa.02-antiplasmin provide inhibitory effect on plasmin in three ways: prevent the binding of plasmin on fibrin; inhibits the proteolytic activity of the enzyme; is covalently attached to fibrin (Dobrovolsky and Titaeva, 2002). In the presence of fast-acting plasmin inhibitor can exhibit its activity only in spot of formation, remains bound to fibrin. If the connection of plasmin to fibrin is broken, and it releases into the blood, thus there is a momentary inactivation of plasmin. Furthermore inhibition of plasmin in the blood stream a2-antiplasmin has an important role in the stabilization of fibrin. During fibrin polymerization plasminogen and a2-antiplasmin incorporated in approximately equal amounts. Moreover, a2-antiplasmin binds and then stitched with the factor XIIIa which that part of fibrin, which is primarily cleaved by plasmin (Kimura and Aoki, 1987; Weisel et al., 1999).

Determination of fibrinolytic potential is important criteria system status of fibrinolysis, its ability to prevent thrombotic complications. In this frame the purpose of this study is to investigate the fibrinolytic potential changes in the organism under the different subtypes of ischemic stroke in both the acute phase of the disease and one year after suffering disease. Potential fibrinolytic system was evaluated determining total time euhlobulins lysis, activity of plasminogen, plasminogen tissue activator (tPA) and its inibitors such as $\alpha$-2-antiplasmin, plasminogen activator inhibitor type one (PAI-1), FXII-dependent fibrinolysis.

\section{MATERIALS AND METHODS}

Blood plasma samples were taken from 35 healthy donors and 123 patients: 66 patients with atherothrombotic ischemic stroke (AIS) and 56 patients with cardioembolic ischemic stroke (CIS) during the first 6 hours of the acute phase of the disease onset and after one year past stroke attack from 86 patients: 66 patients with AIS and 56 patients with CIS. Patients were hospitalized in neurological department of the Hospital №4 (Kyiv, Ukraine). The diagnosis of ischemic stroke was confirmed through computed tomography or magnetic resonance imaging. At the first day of admission to hospital, all patients received aspirin $325 \mathrm{mg}$ orally, then $100 \mathrm{mg}$ aspirin daily. From the second day of hospital stay, patients received low molecular weight heparin in prophylactic dose. All donors and patients or their relatives had been warned about the conduct of clinical research and provided written agreement about participation. Current experiment was approved by the ethics committee from ESC "Institute of Biology and medicine", Kyiv, Ukraine.

Fasting blood samples were collected from the cubital vein of all patients on the 1st day of hospitalization as well as from the absolutely same group of patients one year past acute phase of disease. Blood was collected into 3.8\% sodium citrate (9:1). Blood plasma was separated by further centrifugation at 2,000g for 15 $\mathrm{min}$ at the room temperature and stored at $-20^{\circ} \mathrm{C}$ until assays were performed.

The plasma levels of plasminogen activator inhibitor-1 (PAI-1) and tissue plasminogen activator (t-PA) were measured by standard enzyme linked immunosorbent assay (ELISA) techniques 
(Hockfield et al., 1991; Kemeny, 1991). The ELISA plates were coated overnight at $4^{\circ} \mathrm{C}$ with blood plasma samples previously diluted 10-fold with $50 \mathrm{mM}$ Tris- $\mathrm{HCl}$ containing $130 \mathrm{mM} \mathrm{NaCl}$, $\mathrm{pH}$ 7.4. After being washed, plates were blocked with $5 \%$ nonfat dry milk in $50 \mathrm{mM}$ Tris- $\mathrm{HCl}$ containing $130 \mathrm{mM} \mathrm{NaCl}$, pH 7.4 for $1 \mathrm{~h}$ at $37^{\circ} \mathrm{C}$ and washed again. Then plates were incubated for $1 \mathrm{~h}$ at $37^{\circ} \mathrm{C}$ with specific primary antibodies against the t-PA, PAI and vWF (Millipore, Germany). Plates were washed and incubated for $1 \mathrm{~h}$ at $37{ }^{\circ} \mathrm{C}$ with corresponding secondary antibodies (Sigma, USA) conjugated to horseradish peroxidase. After washing, substrate (o-phenylenediamine and hydrogen peroxide) was added. Plates were read at $492 \mathrm{~nm}$ by a microplate spectrophotometer (QuantTM, BioTek Instruments, Inc). The healthy donor's samples concentration was set as $100 \%$, and changes in concentration are given as percentage of controls.

For the measuring of potential plasminogen activity the medium of incubation included $50 \mathrm{mM}$ Tris- $\mathrm{HCl}$ containing 130 $\mathrm{mM} \mathrm{NaCl}, \mathrm{pH} \mathrm{7.4;} 25 \mathrm{mkl}$ of blood plasma; $3 \mathrm{mM}$ chromogenic substrate $\mathrm{S}_{2251}$; and $5-10 \mathrm{iu} / \mathrm{ml}$ of streptokinase was prepared (Meltzer, 2010). The incubation in the $37^{\circ} \mathrm{C}$ of medium was performed. Registration of absorption was carried out in two-wave mode at the primary 405 and references $492 \mathrm{~nm}$ wavelength by the microplate spectrophotometer. The intensity of the tested process was proportional to the color intensity followed released of $\mathrm{p}$ nitroaniline from the chromogenic substrate. For the healthy donors blood plasma the plasminogen activity was equal $100 \pm 5$ $\%$ (Kozlov et al., 2013).

To determine the $\alpha 2$-antiplasmin activity the analogical procedure was performed (Ząbczyk et al., 2011). But instead of streptokinase the $0.5 \mathrm{cu} / \mathrm{ml}$ of plasmin was add. For the healthy donors blood plasma the $\alpha 2$-antiplasmin activity was equal $80-100$ $\%$ (Kozlov et al., 2013).

For the measurement of Hegeman (FXIIa) dependent fibrinolysis the mixture was prepared: $8 \mathrm{ml}$ of $\mathrm{H}_{2} \mathrm{Odis} ; 0.2 \mathrm{ml}$ of $1 \%$ acetic acid; $0.5 \mathrm{ml}$ of blood plasma and $0.5 \%$ kaolin. The mixture is carefully stirred and incubated at $37^{\circ} \mathrm{C}$ for 30 minutes, then centrifuged for 6 minutes at $1500 \mathrm{rpm}$. The precipitate was dissolved in $0.5 \mathrm{ml}$ of $50 \mathrm{mM}$ Tris- $\mathrm{HCl}$ containing $130 \mathrm{mM} \mathrm{NaCl}$, $\mathrm{pH}$ 7.4. Clot formation was induced by addition of the equal volume of $0.025 \mathrm{M}$ calcium chloride solution. After clot formation the time (in minutes) of complete clot lysis was determined (Kozlov et al., 2013).

At the next step the determination of the time for euglobulin's fraction lysis in blood plasma was performed. In a conical glass tube $0.2 \mathrm{ml}$ of blood plasma; $1,8 \mathrm{ml}$ of $\mathrm{H}_{2}$ Odis; 150 $\mathrm{ml}$ of $0.25 \%$ acetic acid were added. The mixture was carefully stirred and incubated for $30 \mathrm{~min}$ at $4{ }^{\circ} \mathrm{C}$. Fraction of euglobulins was precipitated by centrifugation at $700 \mathrm{~g}$ for $15 \mathrm{~min}$ per $4^{\circ} \mathrm{C}$. The precipitate was dissolved in $250 \mathrm{ml} 50 \mathrm{mM}$ Tris- $\mathrm{HCl}$ containing $130 \mathrm{mM} \mathrm{NaCl}, \mathrm{pH} 7.4$ (Bratchik, 1993). The total fibrinolytic activity was determined by the time (in hours) of complete lysis of fibrin clot formed in blood plasma from the euglobulins faction which was induced by addition of the equal volume of 0.025 M calcium chloride solution (Hrytsiuk, 1994).

\section{RESULTS AND DISCUSSION}

The potential of fibrinolysis depend upon the regulation of the plasminogen conversion to plasmin. The activity of plasmin is tightly regulated by three main components of the plasminogen activator system: plasminogen; tissue-type plasminogen activators; urokinase type plasminogen activators; and plasminogen activator inhibitor type 1 . Important that cascade is modulated by feedback loops that include $\mathrm{Pg}$ and activator inhibitor 1.

To characterize the fibrinolytic level of hemostasis its key parameters were analyzed (Table 1).

The proteolytic activity of plasmin is the principal determinant of the degree of proteolysis and fibrinolysis at the sites of vascular injury. The activity of plasmin is tightly regulated by three main components of the plasminogen activator (PA) system: plasminogen (Plg), plasminogen activators urokinase type (uPA), and tissue-type (tPA); and plasminogen activator inhibitor-1 (PAI1). Results suggest the lower activity of Pg as well as its inhibitor in blood plasma of the patients with ischemic stroke both in acute phase and one year past. In acute phase the Pg activity of patients with AIS was on the $15 \%$ lover in comparison with healthy donors. Besides one year past acute phase the level of Pg activity become closer to the norm and was on the $9 \%$ lover for the patients with AIS. Even one year past stroke attack the disorders in fibrinolysis still saved. Maybe for the full rehabilitation longer period is required.

The level of Pg inhibitors in the patients with stroke showed the controversial results. Pathological conditions observed during the acute phase of both subtype of ischemic stroke were accompanied with abnormal level of t-PA and PAI-1 (Figure 1, 2). The changes in the level are given as percentage of controls. Some amount of patients with the level of inhibitors close to the norm observed in patients with both subtypes of ischemic stroke. $25 \%$ of the patients one year past CIS showed the higher level of PAI-1 on the $30-35 \%$. And just $15 \%$ of the patients with acute CIS had a higher level of PAI-1 on the $20 \%$. The $20 \%$ of the patients with one year past AIS showed on the 30-35\% higher level of the PAI1. And according the acute AIS $40 \%$ of the patients had on the $20 \%$ higher level of PAI-1. For the tPA level the analogical situation was observed for both subtypes of stroke. Moreover one year past stroke some amount of the people with the lover level of tPA in comparison with the norm was showed. Thus $10 \%$ of the acute CIS patients had on the $20 \%$ higher tPA level. One year past CIS $35 \%$ of the patients showed on the $20 \%$ higher level but $15 \%$ of the patients had the $25-30 \%$ lower level of tPA. $50 \%$ of the acute AIS patients showed on the 20-25\% higher tPA level but one year past $55 \%$ of the patients had on the $20-40 \%$ higher level and $20 \%$ of the patients on the $25-30 \%$ lower tPA level. Analysis of PAI-1 level in stroke conditions, showed a close relationship with concentration of tPA in blood plasma. No doubt the fact that $90 \%$ of PAI-1 aimed to inhibit the physiological action of tPA in the bloodstream. Any violation of such connection may be due to adaptive or compensatory phenomena in the hemostatic system during this pathological state of the organism. 


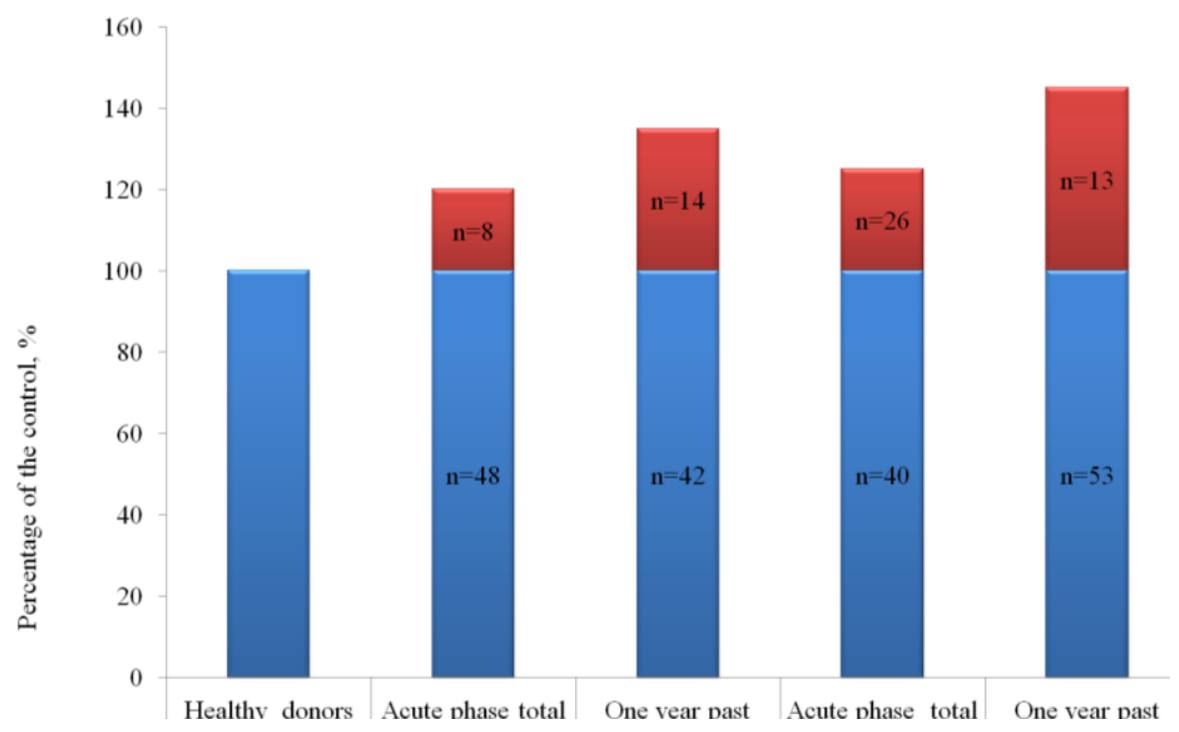

Fig. 1: Level of the PAI- 1 in the blood plasma of patients with ischemic stroke.

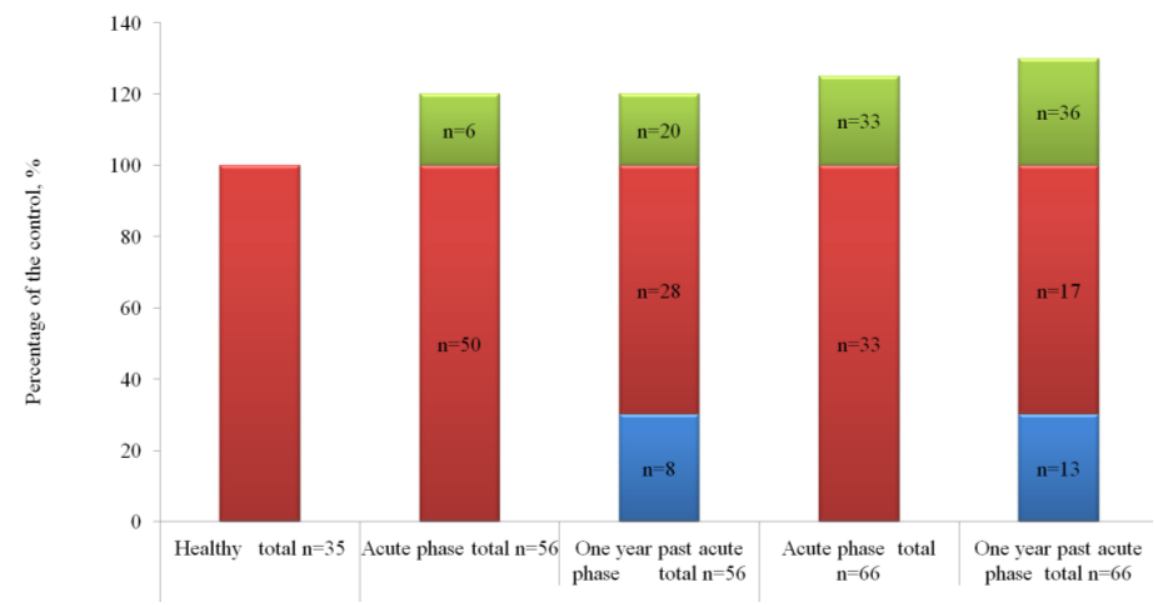

Fig. 2: Level of the tPA in the blood plasma of patients with ischemic stroke.

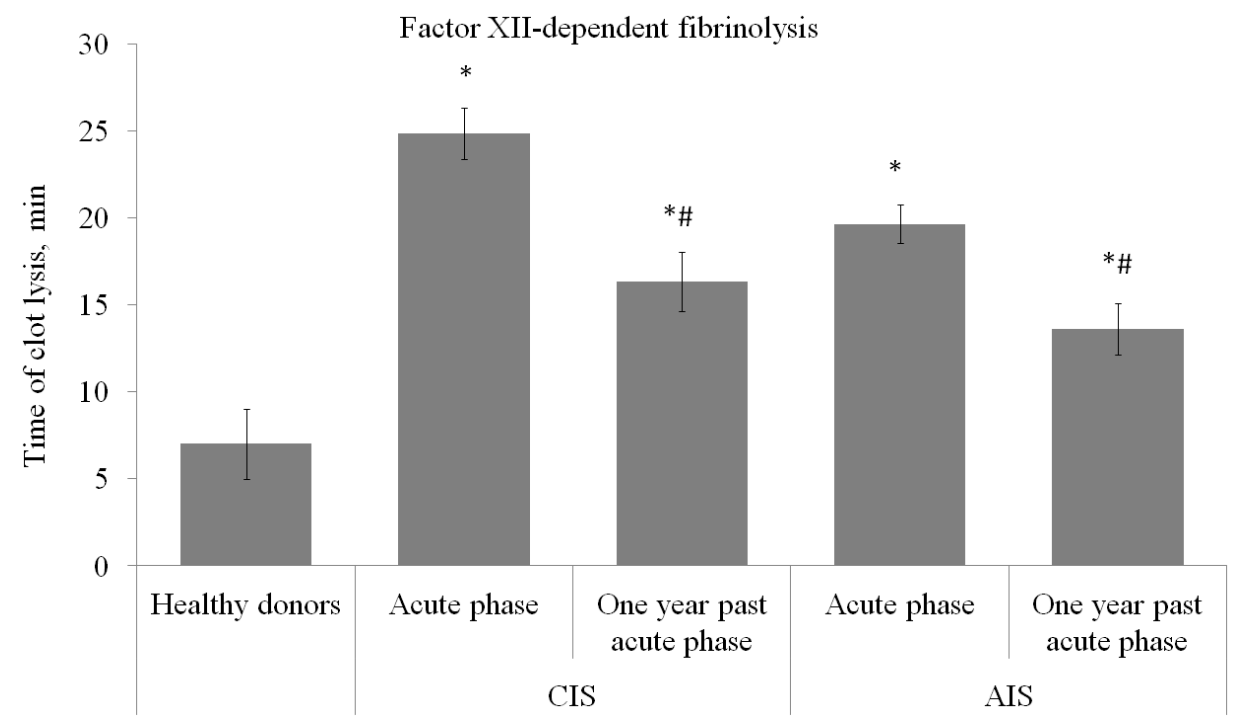

Fig. 3: The level of FXIIa-dependent fibrinolusis in patients with ischemic stroke.

*Statistically significant changes in comparison with healthy donors, \# statistically significant changes in comparison with acute phase. 


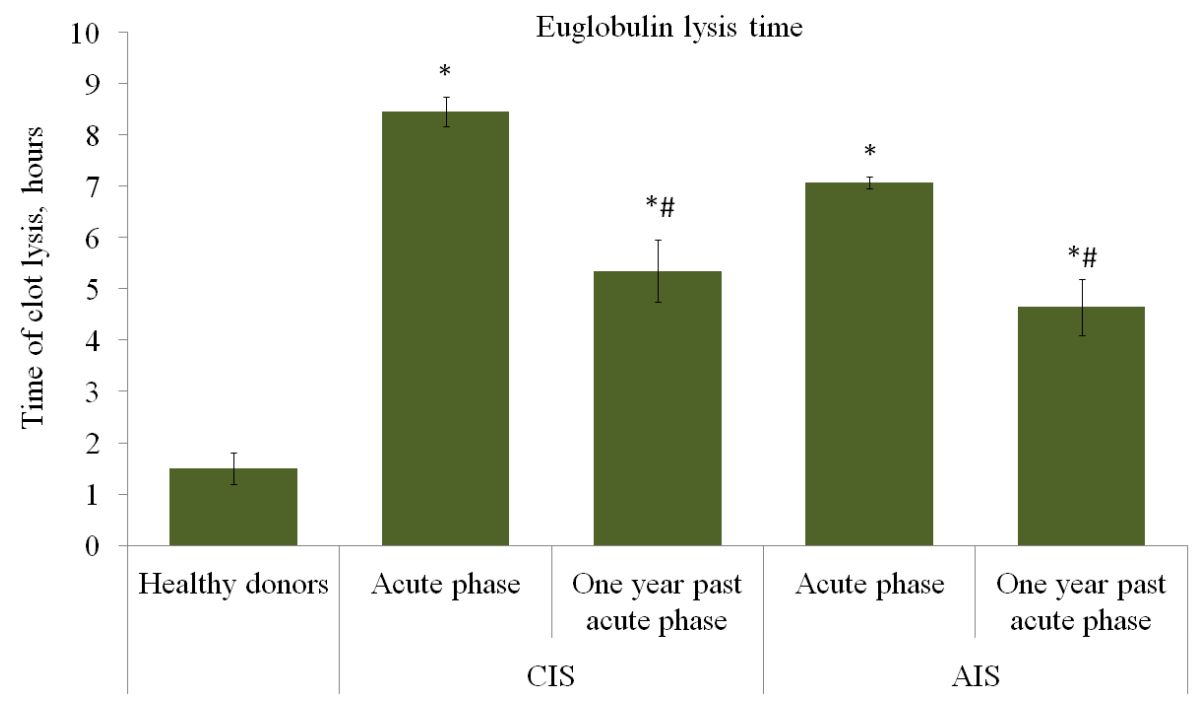

Fig. 4: The time of euglobulin fraction lysis in patients with ischemic stroke.

*Statistically significant changes in comparison with healthy donors, \#Statistically significant changes in comparison with acute phase.

Table 1: Activity of plasminogen and $\alpha 2$-antiplasmin in stroke patients

\begin{tabular}{cccccc}
\hline \multirow{2}{*}{$\begin{array}{c}\text { Activity of the tested } \\
\text { parameter }\end{array}$} & \multirow{2}{*}{$\begin{array}{c}\text { Healthy } \\
\text { donors }\end{array}$} & Acute phase & One year past acute phase & Acute phase & One year past acute phase \\
\cline { 3 - 6 } & \multirow{2}{*}{$100 \pm 5, \%$} & $88.3 \pm 12.7$ & $93.4 \pm 8.4$ & $86.3 \pm 7.1 *$ & $91.3 \pm 5.5 *$ \\
Plasminogen & & $82.2 \pm 12.6 *$ & $91.1 \pm 6.5$ & $86.2 \pm 5.9 *$ & $91.8 \pm 3.9 *$ \\
\hline 2 -antiplasmin & & &
\end{tabular}

*Statistically significant changes in comparison with healthy donors

The next investigation showed significant extension of level of factor XIIa-dependent fibrinolysis especially for the acute phase of the both stroke subtype (Figure 3). Thus for the acute AIS the tested parameters was 2.8 times and for the CIS 3.5 times longer. One year past stroke the indes become more close to the norm but still showed significant disorders in fibrinolysis. For one year past acute phase of AIS the XIIa-dependent fibrinolysis time was 1.9 times and for CIS 2.3 times longer comparing with the healthy donors. Thus, the detected changes are the evidence of the low fibrinolytic capacity of blood plasma of the stroke patients even one year past stroke attack.

Another one index of the state of fibrinolysis is the time of euglobulin fraction lysis. As known the main factors which determine current index are the PAI-1, Pg, FII and $\alpha 2$-antiplasmin. Thus euglodulin lysis time was significant extended for all tested group of patients (Figure 4). In average it was 5 times longer for both subtypes of acute ischemic stroke and 3 times longer one year past acute phase stroke.

\section{CONCLUSION}

Analysis of fibrinolytic level of the haemostasis system of the patients with acute ischemic stroke as well as one year past acute phase of ischemic stroke showed significant inhibition of fibrinolytic potential of the organism. Thus the development of both pathological conditions accompanied by lengthening of time of the euhlobulin frsction lysis and FXIIa-dependent fibrinolysis. While for cardioembolic stroke were inherent more threatening performance. Results suggest the lower activity of plasmonogen as well as $\alpha 2$-antiplasmin in blood plasma of the patients with AIS. Tested pathological conditions observed during the acute phase of both subtype of ischemic stroke were accompanied with abnormal level of t-PA and PAI-1. Even one year past stroke attack the disorders in fibrinolysis still saved. Maybe for the full rehabilitation longer period is required.

\section{Financial support and sponsorship: NIL.}

Conflict of Interests: There are no conflicts of interest.

\section{REFERENCES}

Adamson J, Beswick A, Ebrahim S. Is stroke the most common cause of disability? Stroke Cerebrovasc Dis, 2004; 13: 171-177.

Alessi MC, Juhan-Vague I, Declerck PJ, Collen D. Molecular forms of plasminogen activator inhibitor-1 (PAI-1) and tissue-type plasminogen activator (t-PA) in human plasma. Thromb Res, 1991; 62 (4): $275-285$. $1988 ; 527$

Barkagan AP. Hemorrhagic diseases and syndromes. Medicine,

Bratchik AM. Clinical problems fibrinolysis. By: Health Protection, 1993; 344.

Collen D, Lijnen HR. Fibrinolysis and the control of hemostasis. The molecular basis of blood diseases. W.B. Saunders company, 1987; 662 - 679.

Debrock S, Declerck PJ. Identification of a functional epitope in plasminogen activator inhibitor-1, not localized in the reactive center loop. Biochim Biophys Act, 1997; 8: 257 - 266.

Dobrovolsky AB, Titaeva EB. Fibrinolysis system: regulation of activity and physiological functions of its main components. Biochemistry, 2002; 67: 116 - 127.

Henri R. Lijnen HR., Collen D. Endothelium in haemostasis and thrombosis. Progress in Cardiovascular Diseases, 1997; 39: 343 - 350. 
Hockfield S, Carlson S, Evans C. Selected methods for antibody and nucleic acid probes. 1991; 4(1): 679.

Hrytsiuk oh. Practical hemostasiology. Health, 1994; 256.

Ichinose A, Fujikawa K, Suyama T. The activation of prourokinase by plasma kallikrein and its inactivation by thrombin. J Biol Chem, 1986; 261 (8): 3486 -3489.

Jonathan W. Sturm, Helen M. Dewey, Geoffrey A. Donnan, et $a l$. Handicap After Stroke: How Does It Relate to Disability, Perception of Recovery, and Stroke Subtype? Stroke, 2002; 33: 762-768. doi:10.1161/hs0302.103815

Katrii T.B, Shandyuk V.Yu, Halenova T.I, Shershnov O.V [et al]. The imbalance of the haemostasis cascade in people suffered ischemic stroke. RJPBCS, 2016; 7(6): 2193 - 2199.

Kemeny MA. Practical Guide to ELISA. 1991; NY: Pergamon

Press

Kimura S, Aoki N. Cross-linking site in fibrinogen for alpha 2plasmin inhibitor. J Biol Chem, 1986; 261 (33): 15591-5.

Kozlov, the AA, AL Berkovskii, Katchalov ND, [et al]. Manual for laboratory doctors. Working with koagulometers "Renam" reagents. M: Print, 2013; 44.

Lijnen HR. Patophysiology of the plasminogen/plasmin system. Int. J. Clin. Lab. Res, 1996; 26: 1 - 6. PMID: 8739849.

Lijnen HR. Elements of the fibrinolytic system. Ann NY Acad. Sci, 2001; 936: 226 - 236.

Lowe G, Rumley A, Whincup P, Danesh J. Hemostatic and rheological variables and risk of cardiovascular disease. Semin Vasc Med, 2002; 2: 429-440. doi:10.1093/eurheartj/eh1441

Macfarlane RG, Lond MD, Pilling J, Manc BSc. Observation on fibrinolysis plasminogen, plasmin, and antiplasmin content of human blood. The Lancet, 1946; 248: 562-565.

Mehta SR, Yusuf S. Short- and long-term oral antiplatelet therapy in acute coronary syndromes and percutaneous coronary intervention. JACC, 2003; 41: 79S-88S. PMID:12644345

Meltzer ME, Lisman T, De Groot PG, [et al] Venous thrombosis risk associated with plasma hypofibrinolysis is explained by elevated plasma levels of TAFI and PAI-1. Blood, 2010; 116: 113 - 121.

Raum D, Marcus D, Apler CA, Levey R, Taylor PD, Starrl IE. Synthesis of human plasminogen by the liver. Science, 1980; 208: 1036 1037.

Silverstein RL, Nachman RL, Leung LL, Harpel PC. Activation of immobilized plasminogen by tissue activator. Multimolecular complex formation. J. Biol.Chem, 1985; 260: 10346 - 10352.

Smith O, Gilbert M, Owen WG, Tissue plasminogen activator release in vivo in response to vasoactive agents. Blood, 1985; 66(3): 835 839

Stack S, Gonzalez-Gronow M, Pizzo SV. Regulation of plasminogen activation by components of the extracellular matrix. Biochemistry, 1990; 29: 4966 - 4970.

Stefansson S, Haudenschild C, Lawrence DA. Beyond fibrinolisis: the role of plasminogen activator inhibitor and vitronectin in vascular wound healing. Trends Cardiovascular Med, 1998; 8: 175 - 180.

Swarowska M, Polczak A, Pera J, Klimkowicz-Mrowiec A, Slowik A, Dziedzic T. Hyperfibrinogenemia predicts long-term risk of death after ischemic stroke. J. Thromb. Thrombolysis, 2014; 38: 517-521. PMID:25106735

Vyeremyeyenko KN, Goloborodko OP, Kizim OI. Proteolysis in normal and pathological conditions. Health 1988; 200.

Wallen P, Wiman B. Characterization of human plasminogen. Biochem. Biophys. Acta, 1970; 221: 20-30.

Weisel JW, Veklich Y, Collet JP, Francis CW. Structural studies of fibrinolysis by electron and light microscopy. Thromb Haemost, 1999; 82: 277 - 82

Wolfe C.D.A. The impact of stroke. Brit.Med.Bull, 2000; 56(2): 275-286. PMID:11092079

Ząbczyk M, Majewski J, Lelakowski J. Thromboembolic events are associated with prolonged clot lysis time in patients with permanent atrial fibrillation. Pol. Arch. Med. Wewn, 2011; 1 (121) 11: 400 - 407.

Zubayrov DM. Molekylare fundamentals of coagulation and thrombosis and blood. Feng, 2000; 364.
Adamson J, Beswick A, Ebrahim S. Is stroke the most common cause of disability? Stroke Cerebrovasc Dis, 2004; 13: 171-177. PMID:17903971

Jonathan W. Sturm, Helen M. Dewey, Geoffrey A. Donnan, et al. Handicap After Stroke: How Does It Relate to Disability, Perception of Recovery, and Stroke Subtype? Stroke, 2002; 33: 762-768. doi:10.1161/hs0302.103815

Wolfe C.D.A. The impact of stroke. Brit.Med.Bull, 2000; 56(2): 275-286. PMID:11092079

Lowe G, Rumley A, Whincup P, Danesh J. Hemostatic and rheological variables and risk of cardiovascular disease. Semin Vasc Med, 2002; 2: 429-440. doi:10.1093/eurheartj/ehl441

Mehta S. R, Yusuf S. Short- and long-term oral antiplatelet therapy in acute coronary syndromes and percutaneous coronary intervention. JACC, 2003; 41: 79S-88S. PMID:12644345

Swarowska M, Polczak A, Pera J, Klimkowicz-Mrowiec A, Slowik A, Dziedzic T. Hyperfibrinogenemia predicts long-term risk of death after ischemic stroke. J. Thromb. Thrombolysis, 2014; 38: 517-521. PMID:25106735

Macfarlane RG, Lond MD, Pilling J, Manc BSc. Observation on fibrinolysis plasminogen, plasmin, and antiplasmin content of human blood. The Lancet, 1946; 248: 562-565.

Wallen P, Wiman B. Characterization of human plasminogen. Biochem. Biophys. Acta, 1970; 221: 20-30.

Vyeremyeyenko KN, Goloborodko OP, Kizim OI. Proteolysis in normal and pathological conditions. Health 1988; 200.

Zubayrov DM. Molekylare fundamentals of coagulation and thrombosis and blood. Feng, 2000; 364

Lijnen HR. Patophysiology of the plasminogen/plasmin system. Int. J. Clin. Lab. Res, 1996; 26: 1 - 6. PMID: 8739849.

Collen D, Lijnen HR. Fibrinolysis and the control of hemostasis. The molecular basis of blood diseases. W.B. Saunders company, 1987; 662 - 679.

Raum D, Marcus D, Apler CA, Levey R, Taylor PD, Starrl IE. Synthesis of human plasminogen by the liver. Science, 1980; 208: 1036 1037.

Smith O, Gilbert M, Owen WG, Tissue plasminogen activator release in vivo in response to vasoactive agents. Blood, 1985; 66(3): 835 839.

Katrii T.B, Shandyuk V.Yu, Halenova T.I, Shershnov O.V [et $a l]$. The imbalance of the haemostasis cascade in people suffered ischemic stroke. RJPBCS, 2016; 7(6): 2193 - 2199.

Dobrovolsky AB, Titaeva EV. The fibrinolysis system: regulation of activity and physiologic functions of its main components. Lancet, 2002;355: 1627 - 1632

Silverstein RL, Nachman RL, Leung LL, Harpel PC. Activation of immobilized plasminogen by tissue activator. Multimolecular complex formation. J. Biol.Chem, 1985; 260: 10346 - 10352.

Stack S, Gonzalez-Gronow M, Pizzo SV. Regulation of plasminogen activation by components of the extracellular matrix. Biochemistry, 1990; 29: 4966 - 4970.

Lijnen HR. Elements of the fibrinolytic system. Ann NY Acad. Sci, 2001; 936: 226 - 236.

Ichinose A, Fujikawa K, Suyama T. The activation of prourokinase by plasma kallikrein and its inactivation by thrombin. J Biol Chem, 1986; 261 (8): 3486 -3489. $1988 ; 527$

Barkagan AP. Hemorrhagic diseases and syndromes. Medicine,

Stefansson S, Haudenschild C, Lawrence DA. Beyond fibrinolisis: the role of plasminogen activator inhibitor and vitronectin in vascular wound healing. Trends Cardiovascular Med, 1998; 8: 175 180.

Debrock S, Declerck PJ. Identification of a functional epitope in plasminogen activator inhibitor-1, not localized in the reactive center loop. Biochim Biophys Act, 1997; 8: 257 - 266.

Alessi MC, Juhan-Vague I, Declerck PJ, Collen D. Molecular forms of plasminogen activator inhibitor-1 (PAI-1) and tissue-type plasminogen activator (t-PA) in human plasma. Thromb Res, 1991; 62 (4): $275-285$. 
Henri R. Lijnen HR., Collen D. Endothelium in haemostasis and thrombosis. Progress in Cardiovascular Diseases, 1997; 39: 343 - 350.

Kimura S, Aoki N. Cross-linking site in fibrinogen for alpha 2plasmin inhibitor. J Biol Chem, 1986; 261 (33): 15591-5.

Weisel JW, Veklich Y, Collet JP, Francis CW. Structural studies of fibrinolysis by electron and light microscopy. Thromb Haemost, 1999; 82: 277 - 82 .

Hockfield S, Carlson S, Evans C. Selected methods for antibody and nucleic acid probes. 1991; 4(1): 679

Kemeny MA. Practical Guide to ELISA. 1991; NY: Pergamon Press.

Meltzer ME, Lisman T, De Groot PG, [et al] Venous thrombosis risk associated with plasma hypofibrinolysis is explained by elevated plasma levels of TAFI and PAI-1. Blood, 2010; 116: 113 - 121.

Kozlov, the AA, AL Berkovskii, Katchalov ND, [et al]. Manual for laboratory doctors. Working with koagulometers "Renam" reagents. M: Print, 2013; 44.

Ząbczyk M, Majewski J, Lelakowski J. Thromboembolic events are associated with prolonged clot lysis time in patients with permanent atrial fibrillation. Pol. Arch. Med. Wewn, 2011;1 (121) 11: 400 - 407.

Bratchik AM. Clinical problems fibrinolysis. By: Health Protection, 1993; 344.

Hrytsiuk OH. Practical hemostasiology. Health, 1994; 256.

\section{How to cite this article:}

Katrii T, Shandyuk V, Raksha N, Halenova T, Shershnov O, Melnyk V, Savchuk O. Fibrinolysis parameters in the acute and post ischemic stroke patients. J App Pharm Sci, 2017; 7 (04): 096102. 